\title{
Ten-Year Risk of Fatal Cardiovascular Disease and its Association with Metabolic Risk Factors Among Waste Pickers in South Africa
}

\section{Felix Made ( $\square$ FelixM@nioh.ac.za )}

National Institute for Occupational Health https://orcid.org/0000-0003-0052-9011

Engelbert A Nonterah

Navrongo Health Research Centre

Nonhlanhla Tlotleng

National Health Laboratory Service

Vusi Ntlebi

National Health Laboratory Service

Nisha Naicker

National Health Laboratory Service

Research article

Keywords: Obesity, hypertension, diabetes, cholesterol, smoking, age, understudied populations

Posted Date: February 16th, 2021

DOI: https://doi.org/10.21203/rs.3.rs-236769/v1

License: (a) This work is licensed under a Creative Commons Attribution 4.0 International License. Read Full License

Version of Record: A version of this preprint was published at BMC Cardiovascular Disorders on July 10th, 2021. See the published version at https://doi.org/10.1186/s12872-021-02150-y. 


\section{Abstract}

\section{Background}

Cardiovascular disease (CVD) is the leading cause of death among non-communicable diseases in South Africa. Several metabolic risk factors contribute to the development of CVD. Informal workers such as waste pickers could be unhealthy lifestyle naive, and most public health research on CVD does not include this understudied population. This study estimated the 10-year risk of fatal CVD and its association with metabolic risk factors in an understudied study population of waste pickers in Johannesburg, South Africa.

\section{Methods}

A cross-sectional survey was conducted among waste pickers in two landfill sites in Johannesburg. We used the Systematic Coronary Risk Evaluation (SCORE) risk charts to estimate the 10-year risk of fatal CVD. We then employed ordinary least squares regression to assess the association between the 10-year risk of fatal CVD with metabolic risk factors. Other variables adjusted in the regression model were HIV status, education, income, injuries from work, clinic visits in the previous 12 months, and alcohol consumption.

\section{Results}

A total of 370 waste pickers were included in this analysis, $265(73.41 \%)$ were males. The mean age of the participants was 34 years. The majority were between the age of 20 and 39 years. More than $55 \%$ of the waste pickers did not visit a clinic in the previous 12 months, and $68.57 \%$ were smoking. The 10 -year survival probability from CVD was more than $99 \%$ for both males and females. Waste pickers who were overweight/obese, hypertensive, or with an elevated blood glucose level had high statistically significant mean percentages of the 10-year risk of fatal CVD compared to those who did not have the metabolic risk factors.

\section{Conclusions}

Prevention of 10-year risk of fatal CVD in this understudied population of waste pickers should target the control of obesity, hypertension, and diabetes. Health awareness and education for waste pickers will be an important step in reducing the burden of these metabolic risk factors. We further recommend that health systems should recognize waste pickers as a high-risk group and consider extensive CVDs surveillance.

\section{Background}

The mortality rates of non-communicable diseases (NCDs) are higher than that of HIV/AIDS, of which cardiovascular disease (CVD) is the leading cause in South Africa [1, 2]. CVDs are a group of disorders of the heart and the blood vessels, which include coronary heart disease (CHD), stroke, and other vascular 
diseases. According to the World Health Organization (WHO), more people die annually from CVD than any other diseases [3]. The WHO further reported that in the year 2016, about 17.9 million people died from CVD, which accounted for $31 \%$ of all global deaths. Over $80 \%$ of the CVD deaths take place in lowand middle-income countries.

The World Heart Federation (WHF) initiated a CVD prevention and control program called 25 by 25 Global Target. This initiative aimed to reduce the premature mortality rate from CVD by $25 \%$ in 2025 [4]. In South Africa, various efforts including a plan to reduce NCDs by $25 \%$ by 2020 was set alongside increased taxation of sugar and tight tobacco legislation $[1,5]$. Other efforts have been placed on improved treatment of cardiovascular diseases in South Africa and identification of risk factors [6].

A rapid rise in development and urbanization has led to many people practicing unhealthy lifestyles, which increases the prevalence of metabolic risk factors. These risk factors include high body mass index (BMI), raised blood pressure, blood glucose, and elevated cholesterol level [3, 7]. The metabolic risk factors are the major determinants of CVD according to the WHO [3]. Underlying modifiable risk factors such as tobacco use, alcohol abuse, physical inactivity, and a poorly balanced diet could increase the risk of developing CVD among waste pickers, where unhealthy lifestyle practices are probably high. A high unemployment rate $(26.7 \%)$ and increased urbanization, are associated with a rise in the informal economy, such as waste recycling in South Africa (SA) [8]. Waste pickers contribute to the economy and waste recycling efforts. An estimated 1.5 million tonnes of wastes are dumped in the landfill sites in Johannesburg [9].

Work environments such as the landfill sites have several health hazards such as noise, work stress, chemicals and pollutants, and increased workload. These health hazards were associated with the development of CVD in previous literature $[10,11,12]$. Despite the efforts put in place to reduce the prevalence and incidence of CVD, waste pickers are most likely marginalized within the healthcare system, yet their CVD risk could be very high. The medical recommendation for the prevention of CVD needs to be based on an assessment of the "individual's total risk burden" not on a single risk factor [13, 14]. There is evidence that risk factors tend to occur in clusters [15], and the majority of the individuals have more than one risk factors, which when combined leads to increased fatal CVD risk [16]. As a result, the use of the CVD risk score as the first line of prevention among people who do not clinically indicate CVD symptoms is highly recommended [17]. This study aimed to estimate the 10-year risk of fatal CVD and assessed its association with metabolic risk factors among an understudied population of waste pickers in Johannesburg, South Africa.

\section{Methods}

\subsection{Study Design and Setting}

This study was a cross-sectional survey conducted in two of the largest landfill sites in Johannesburg. The landfill sites were closer to densely populated areas, with the largest number of waste pickers in 
Johannesburg. One of the study sites had approximately 600 waste pickers and the other had approximately 3000 waste pickers.

\subsection{Study Population And Sample>}

The study population included male and female waste pickers aged 18 years or older. A convenience sampling frame was employed to include waste pickers in the study. All waste pickers who were available on the day of data collection were approached. The study aim was explained to each one of them in a language they understand. Those who agreed to a written consent were included in the study.

\subsection{Data Collection Tools And Methods}

A structured questionnaire was translated into languages spoken by individual waste pickers (see supplementary file). Participants' consent was sought and an information sheet was provided to each waste picker by trained fieldworkers, who explained the study objectives and processes involved. Data were imputed directly into the RedCap database using an electronic structured questionnaire. The 10-year risk of fatal CVD was calculated using a comparable method from the European based Systematic Coronary Risk Evaluation (SCORE) project [18]. We opted to use the SCORE methods because the Framingham data and analyses strategy for 10-year risk of fatal CVD tended to overestimate absolute risk in populations with lower coronary heart disease rates $[19,20]$. In this study, we assumed that the waste pickers have low-risk CVD comparable to low-risk countries reported in the SCORE risk function. This is because they constantly do physical activities (a major factor for the development of CVD). The physical activities may include strenuous work in pulling, pushing, bending, and walking during the collection of waste materials. Also, the SCORE risk function allows for variation in the risk of CVD [18]. The risk factors used in the SCORE risk function are widely regarded as the classical CVD risk because of their strong association with CVD. Therefore, we used the SCORE low CVD risk estimates based on gender, age, systolic blood pressure, total cholesterol, and current smoking status. We took anthropometric measurements for weight and height to generate BMI (weight in kilograms per height in meters squared) category: underweight was defined as less than 8.5), the normal weight started from 18.5 to $<25$ ), overweight ( 25 to < 30), and obesity from 30 and above [21]. Systolic and diastolic blood pressure was measured three times, and the average of the three measurements was taken to generate the final variables. Hypertension was defined as systolic blood pressure $>=140 \mathrm{mmHg}$ and/or diastolic blood pressure $>=90 \mathrm{mmHg}$ [21]. Point of care testing was done for random blood glucose. Random blood glucose was used as a proxy to indicate possible diabetes without the diagnosis. The random blood glucose was categorized into three groups with $4.5-7.8 \mathrm{mmol} / \mathrm{L}$ as normal and $7.8-11.1 \mathrm{mmol} / \mathrm{L}$, $>11.1 \mathrm{mmol} / \mathrm{L}$ as moderate and high, respectively [22]. Also, total cholesterol in $\mathrm{mmol} / \mathrm{L}$ was measured. Other self-reported data collected were for education, injuries, clinic visits, alcohol, average monthly income, and HIV. 


\section{Statistical Analysis}

Statistical analysis was undertaken using STATA SE version 15.1 (4905 Lakeway Drive, College Station, TX, USA). Descriptive statistics for continuous variables were summarized as means and standard deviations, factor variables were presented as frequencies and percentages. We used the SCORE method to estimate the 10-year risk of fatal CVD [18]. The cardiovascular risk functions were calculated using a Weibull proportional hazards model for baseline survival function only. The hazard function for men and women were calculated separately, and the risk factor estimate was done for combined sexes. The hazard function was calculated based on the participant's age, to produce an estimate that depends on observed age than using the length of the study period as in traditional survival function. Then the 10year risk of fatal CVD was based on the conditional probability of death in the next 10 years given a participant has survived to the index age. The risk of death was estimated by combining two separate models, one for coronary heart disease (CHD) and another for non-coronary heart disease (non-CHD).

To calculate the 10-year risk for fatal cardiovascular disease, we first estimated the underlying risk for $\mathrm{CHD}$ and non-CHD. This was done separately for participant's current age and their age in 10 years.

\section{Equation 1.}

The survival probability is:

$\mathrm{S}_{0}(\mathrm{age})=\exp \left\{-(\exp (\mathrm{a}))(\right.$ age -20$\left.){ }^{p}\right\}$

$\mathrm{S}_{0}($ age +10$)=\exp \{-(\exp (\mathrm{a}))($ age -10$) p\} *$

Where $\mathrm{a}$ and $p$ are low-risk constant coefficients available in the SCORE report. * Weibull model is expressed as $\lambda=\exp (a)$.

We then calculated the weighted sum, $w$, of risk factors including cholesterol, smoking, and systolic blood pressure, this was also done separately for CHD and non-CHD.

\section{Equation 2.}

$w=\beta_{\text {chol }}($ Cholesterol- 6$)+\beta_{S B P}($ SBP-120 $)+\beta_{\text {smoker }}($ current $)$.

Where $\beta$ is a constant coefficient available in the SCORE report [18].

To get the probability of survival at each age for each cause, we combined the underlying risk for CHD and Non-CHD disease at current participants' age and age in 10 years in Eq. 1, with the weighted sum of participant's risk factors in Eq. 2.

$\mathrm{S}($ age $)=\left[\left\{\mathrm{S}_{0}(\text { age })\right\}^{\exp (w)}\right.$

$\mathrm{S}($ age +10$)=\left\{\mathrm{S}_{0}(\mathrm{age}+10)\right\} \exp (w)$ 
The 10-year survival probability based on a participant's current age and age in 10 years is:

$S_{10}($ age $)=S($ age +10$) / S($ age $)$

The 10-year risk for each point is given by:

Risk $_{10}=1-\mathrm{S}_{10}(\mathrm{age})$

Finally, we combined the risk for CHD and non-CHD to produce the 10-year risk of fatal CVD.

CVDRisk $_{10}($ age $)=[$ CHDRisk(age $\left.)\right]+[$ Non-CHDRisk(age $\left.)\right]$

We then used ordinary least squares regression to assess the association between the 10-year risk of fatal CVD and known metabolic risk factors. To avoid, any spurious finding, we adjusted our model with full variables inclusion and systematic reduction. Separate models were fitted for continuous variables that have been transformed to factor variables, with all other covariates adjusted. We opted to use the bootstrapping technique with maximization of variance-covariance estimation on the log-transformed 10year risk of the fatal CVD response variable. The bootstrapping model produced bias-corrected $95 \%$ confidence intervals from the underlying unobserved clustering from the data.

\section{Results}

A total of 370 waste pickers were included in this study, of which $96(26.59 \%)$ were females (Table 1$)$. The mean age of the participants was 34 years. On average the waste pickers worked for 6.7 years at the landfill sites. The participants on average earned more than 117.24 United States Dollars monthly. The majority of the participants were in the age group 20 to 39 years old. More than $79 \%$ had reached at least a secondary education level. There were $146(41.24 \%)$ waste pickers who at least visited a clinic in the previous year. The number of those currently smoking was 240 (68.57\%). A proportion of $41.73 \%$ of the waste pickers was currently consuming alcohol consumption. At least $80 \%$ of the waste pickers had some sort of injuries from sharp objects or any form during their work at the landfill sites. The majority (88.41\%) of them were HIV negative. Most of the waste pickers were of normal weight 202 (54.89\%), nonhypertensive 288 (77.84\%), and had normal random blood glucose level 362 (97.84\%). 
Table 1

Description of demographic, lifestyle, and metabolic risk factors

\begin{tabular}{|ll|}
\hline Continuous variables & Mean (standard deviation) \\
\hline Age (years) & $34.00(10.00)$ \\
\hline Years of work & $6.70(5.50)$ \\
\hline Income (United States Dollars) & $123.58(136.05)$ \\
\hline BMI (kg/m ${ }^{2}$ ) & $22.71(6.59)$ \\
\hline Blood glucose (mmol/L) & $5.10(2.43)$ \\
\hline Total cholesterol (mmol/L) & $3.23(1.33)$ \\
\hline Systolic blood pressure (mmHg) & $120.30(21.31)$ \\
\hline Diastolic blood pressure (mmHg) & $76.46(17.29)$ \\
\hline Factor variables & $\mathrm{n}(\%)$ \\
\hline Sex & \\
\hline Male & $265(73.41)$ \\
\hline Female & $96(26.59)$ \\
\hline Age group & \\
\hline Less than 20 & $6(1.62)$ \\
\hline $20-29$ & $139(37.57)$ \\
\hline $30-39$ & $136(36.76)$ \\
\hline $40-49$ & $38(10.27)$ \\
\hline $50+$ & $51(13.78)$ \\
\hline Education & \\
\hline None & $286(79.44)$ \\
\hline Primary & \\
\hline Secondary & \\
\hline Clinic visits & \\
\hline No & \\
\hline Yes & \\
\hline Smoking status & \\
\hline
\end{tabular}




\begin{tabular}{|ll|}
\hline Continuous variables & Mean (standard deviation) \\
\hline No smoking & $110(31.43)$ \\
\hline Currently smoking & $240(68.57)$ \\
\hline Alcohol & $162(58.27)$ \\
\hline No & $116(41.73)$ \\
\hline Yes & \\
\hline Injuries & $62(17.27)$ \\
\hline No & $297(82.73)$ \\
\hline Yes & \\
\hline HIV & $305(88.41)$ \\
\hline No & $40(11.59)$ \\
\hline Yes & \\
\hline BMl category & $83(22.55)$ \\
\hline Underweight & $202(54.89)$ \\
\hline Normal weight & $40(10.87)$ \\
\hline Overweight & $43(11.68)$ \\
\hline Obese & $4(1.08)$ \\
\hline Hypertension & $288(77.84)$ \\
\hline Non-hypertensive & $82.16)$ \\
\hline Hypertensive & \\
\hline Blood glucose category & \\
\hline Normal & \\
\hline Moderate & \\
\hline High & \\
\hline
\end{tabular}

Table 2 presents the distribution of participants, the 10-year risk of fatal CVD, and the 10-year survival probability from CVD by sex. The 10-year risk of fatal CVDs increased with increasing age in both sexes. Waste pickers at the age of 50 or more had a high 10-year risk of fatal CVDs, which had a slightly higher average in males (1.62) than females (1.22). The majority of the participants had normal weight in both males and females. Waste pickers that had a normal weight revealed a high 10-year risk of fatal CVD followed by overweight participants, especially in females. Females that indicated a high glucose level or 
were hypertensive and males that were hypertensive recorded a high 10-year fatal CVD risk. A male participant who was categorized with high blood glucose concentration had a lower 10-year risk of fatal CVD than those with normal or moderate blood glucose levels. The 10-year survival probability of CHD and non-CHD were similar at more than $99 \%$ probability (the chance of not dying from CVD) of survival from any fatal CVD events. 
Table 2

The distribution of age group, the 10-year risk of fatal CVD, and 10-year survival probability by sex.

Male

$\mathrm{n}(\%)$
Female

$\mathrm{n}(\%)$

10-year CVD risk

Mean (SD)

$0.340(2.209)$
Variables

Age group (years)

Less than 20

$20-29$

$30-39$

$40-49$

$50+$

$16(6.02)$

$5(1.89)$

(46.42)

100

(37.74)
(SD)

$0.130(0.584)$

$123 \quad 0.004(0.004)$

$21(7.92)$

$0.301(0.328)$

$1.621(1.811)$
$1(1.04)$

16

(16.67)

$1.7 \times 10^{-5}\left(1.5 \times 10^{-}\right.$

$\left.{ }^{5}\right)$

$36 \quad 0.007(0.012)$

(37.60)

17

(17.71)

0.062(0.048)

26

(27.08)

$1.220(4.216)$

\section{BMl category}

Underweight

70 (26.62)

$0.139(0.727)$

13

(13.54)

$0.035(0.118)$

50

(52.08)

0.559 (3.119)

(55.87)

$0.155(0.599)$

Obese

\section{Blood glucose category}

Normal

263

(99.27)

Moderate

High

Hypertension

Non-hypertensive

$1(0.38)$

$1(0.38)$
$24(9.13)$

$0.102(0.174)$

14

(14.58)

$22(8.37)$

$0.069(0.159)$

19.

(19.79)

$0.038(-)$

$0.141(0.587)$

$0.002(-)$

$91 \quad 0.340(2.270)$

(94.79)

$0.209(0.272)$

$0.115(0.204)$
2 (2.08) $0.311(0.419)$

$3(3.13)$

$0.368(0.449)$

$3(3.13) \quad 0.368(0.449)$

65
$(67.71)$

65
$(67.71)$
$0.074(0.157)$

$0.077(0.425)$ 


\begin{tabular}{|lllll|}
\hline \multicolumn{2}{|c|}{ Male } & \multicolumn{3}{c|}{ Female } \\
\hline Hypertensive & $49(18.49)$ & $0.451(1.019)$ & 31 & $0.872(3.806)$ \\
& & & $(32.29)$ & \\
& & 10 -year survival probability of CVD & \\
\hline CHD & - & $99.82 \%(0.10 \%)$ & - & $99.80 \%(0.10 \%)$ \\
\hline Non-CHD & - & $99.90 \%(0.04 \%)$ & - & $99.70 \%(1.71 \%)$ \\
\hline SD: Standard deviation & & & & \\
\hline
\end{tabular}

Table 3 presents the association between the 10-year risk of fatal CVD and metabolic risk factors. BMI and hypertension were independently associated with a 10-year risk of fatal CVD after adjusting for HIV, income, educational status, number of years of work, clinic visits in the past months, injuries at work, and alcohol consumption. For a unit increase in $\mathrm{BMI}$, there was a $2.53 \%$ average increase in 10 -year risk fatal CVD events. Overweight participants had a statistically significant increase in the 10-year risk of fatal CVD (mean: $133.96 \%$; 95\% Cl: $1.10 \%$; 493.57\%). Waste pickers who were obese also had a $20.92 \%$ increase in 10-year risk of fatal CVD events but the difference was not significant compared to those who were underweight. There was a $469.73 \%$ mean increase in the 10 -year risk of fatal CVD with a statistically significant difference compared to the normal or non-hypertensive individuals. Blood glucose was not significantly associated with a 10 -year risk of fatal CVD in the study population. 
Table 3

Association between the 10-year risk of fatal CVD and metabolic risk factors

\begin{tabular}{|llll|}
\hline Factors & Mean (\%) & LCL(\%) & UCL (\%) \\
\hline BMI & 2.53 & -0.69 & 5.44 \\
\hline BMI category & & & \\
\hline Underweight & 0 & & 107.71 \\
\hline Normal & 19.72 & -32.63 & 493.57 \\
\hline Overweight & 133.96 & 1.10 & 192.99 \\
\hline Obese & 20.92 & -45.61 & 9.85 \\
\hline Blood glucose & 4.08 & -8.24 & 586.20 \\
\hline Blood glucose category & & & 1064.64 \\
\hline Normal & 0 & -83.56 & \\
\hline Moderate & -2.95 & -22.66 & \\
\hline High & 343.70 & & \\
\hline Hypertension status & & & \\
\hline Non-hypertensive & 0 & & \\
\hline Hypertensive & 469.73 & & \\
\hline $\begin{array}{l}\text { LCL: Lower confidence limit } \\
\text { UCL: Upper confidence limit } \\
\text { Adjusted for HIV, income, education status, number of years of work, clinic visits in the past } \\
\text { months, injuries at work, and alcohol consumption }\end{array}$ & & \\
\hline
\end{tabular}

\section{Discussion}

The prevention of CVD including heart attacks and stroke should be based on a cardiovascular risk assessment which is better than treatment based on a single risk factor [23]. This is largely because CVD risk factors tend to occur in clusters and have pronounced fatal effects than single risk factors $[24,25]$. The 10-year risk of fatal CVD and associated diseases of metabolic risk factors that arise from life style choices among the waste pickers have not been studied to our knowledge. Our study aimed to estimate the 10-year risk of fatal CVD and its association with metabolic risk factors in this largely unhealthy lifestyle naive and vulnerable population.

The average 10-year risk of fatal CVD among female waste pickers was higher than that of males. This is inconsistent with previous literature that showed CVD is more common overall in men than women, due 
to men's risky life style choices [27]. Our finding suggests differences in age, women waste pickers were generally older than men. In addition, the CVD risk could have been increased by lifestyle diseases including high blood glucose, hypertension, and obesity which tend to be more prevalent in women in this study. Our study indicated that increasing age increases the 10-year risk of fatal CVD in both men and women, this is in line with a previous report where CHD, a major CVD, increases with increasing age in both genders, and even more common in individuals older than 50 years [24]. In another study, men had almost doubled the 10-year risk for CVD compared to women at both baseline and 1-year follow-up [28].

A male participant with a high blood glucose level had a lower 10-year risk of fatal CVD than those who had normal or moderate blood glucose levels. This might be attributed to the knowledge of the disease which comes with healthy lifestyle choices in certain individuals. Hence other CVD-related risk factors are adequately managed. A high mean percentage increase in 10-year risk of fatal CVD events was associated with waste pickers who were overweight or obese, high blood glucose level, and hypertensive. According to the WHO, hypertension, increased blood glucose (diabetes) and obesity are the major metabolic risk factors for the development of CVD. Studies conducted on Brazilian waste pickers found that hypertension, diabetes, overweight, and obesity were very prevalent $[29,30]$. This may imply that these metabolic risk factors are common in waste pickers even if they are of different geographic locations and share different cultural practices. Social, economic, and cultural change and poverty including stress were reported to be the drivers of these lifestyles diseases [3]. The waste pickers could be affected the worst given their level of poverty and stress, as they strive on daily basis to earn a living. Also, waste pickers might have no or rare access to healthcare, as reported previously [31]. Furthermore, another study reported that $37 \%$ of the waste pickers did not consult a doctor in more than a year and $8 \%$ never measured their blood pressure including other health measurements [29].

One of the limitations of this study was the small sample size which could have inflated the findings from this study and thus hide potential significant effect. The SCORE risk function was not validated in the black population, thus it may under or over-estimate 10-year CVD risk. Inaccurate information might have also been given by the participants since they would not like to be seen practicing bad health habits by the research interviewers. The inclusion of waste pickers from 18 years old unlike in previous studies where only individuals from 40 years and older, could contribute to the low risk of fatal CVD [18, 32, 33]. Despite these limitations, our study does offer some insights on the 10-year risk of fatal CVD in a largely understudied population. It will serve as the basis to establish a large scale cohort of waste pickers for further research.

\section{Conclusions}

Prevention of 10-year risk of fatal CVD in this understudied population of waste pickers should target the control of obesity, hypertension, and diabetes. Therefore, health awareness and education for waste pickers will be an important step in reducing these metabolic risks. We further recommend that health systems should recognize waste pickers as a high-risk group and consider extensive CVDs in near future. 


\section{Abbreviations}

NCD

Non-communicable diseases

CVD

Cardiovascular diseases

SCORE

Systematic Coronary Risk Evaluation

BMI

Body mass index

\section{Declarations}

\section{Ethics approval and consent to participate}

Ethical clearance for this study was obtained from the Human Research Ethics Committee (HREC) of the University of the Witwatersrand with clearance number: M171120.

\section{Consent for publication}

Not applicable

\section{Availability of data and materials}

The datasets used and/or analysed during the current study are available from the corresponding author on reasonable request.

\section{Competing interests}

The authors declare that they have no competing interests.

\section{Funding}

This research received no external funding.

\section{Authors' contributions}

FM conceptualized, analysed, and wrote the entire first draft. EAN was a major contributor in writing and improving the overall content of the manuscript. NT, VN, and NN contributed to the method and critical review of the manuscript. All authors have read and agreed to the published version of the manuscript.

\section{Acknowledgments}

The authors will like to acknowledge the waste pickers who took the time to participate in the study procedures and to offer relevant information about themselves. We also appreciate the role of $\mathrm{NIOH}$ in 
initiating and coordinating the study.

\section{References}

1. Schutte AE. Urgency for South Africa to prioritise cardiovascular disease management. Lancet Glob Health. 2019;7(2):e177-8.

2. Nojilana B, Bradshaw D, Pillay-van Wyk V, Msemburi W, Somdyala N, Joubert JD, Groenewald P, Laubscher R, Dorrington RE. Persistent burden from non-communicable diseases in South Africa needs strong action. SAMJ. 2016;106(5):436-7.

3. WHO. Cardiovascular diseases (CVDs). 2017. Available from: https://www.who.int/news-room/factsheets/detail/cardiovascular-diseases-(cvds). [cited 2020 Dec 15].

4. Solimene MC. Coronary heart disease in women: a challenge for the 21 st century. Clinics. 2010;65(1):99-106.

5. National Department of Health. Strategic plan for the prevention and control of non-communicable diseases 2013-17. Pretoria: National Department of Health; 2013.

6. Basu S, Wagner RG, Sewpaul R, Reddy P, Davies J. Implications of scaling up cardiovascular disease treatment in South Africa: a microsimulation and cost-effectiveness analysis. Lancet Glob Health. 2019;7(2):e270-80.

7. Aryal KK, Mehata S, Neupane S, Vaidya A, Dhimal M, Dhakal P, Rana S, Bhusal CL, Lohani GR, Paulin $\mathrm{FH}$, Garg RM. The burden and determinants of non-communicable diseases risk factors in Nepal: findings from a nationwide STEPS survey. PloS One. 2015;10(8):e0134834.

8. Statistics South Africa. Quarterly Labour Force Survey. 2018. Available from: http://www.statssa.gov.za/publications/P0211/P02111stQuarter2018.pdf [cited 2020 July 3]).

9. Rasmeni ZZ, Madyira DM. A Review of the Current Municipal Solid Waste Management Practices in Johannesburg City Townships. Procedia Manuf. 2019;35:1025-31.

10. Gan WQ, Moline J, Kim H, Mannino DM. Exposure to loud noise, bilateral high-frequency hearing loss and coronary heart disease. Occup Environ Med. 2016;73(1):34-41.

11. Backé EM, Seidler A, Latza U, Rossnagel K, Schumann B. The role of psychosocial stress at work for the development of cardiovascular diseases: a systematic review. Int Arch Occup Environ Health. 2012;85(1):67-79.

12. Miller KA, Siscovick DS, Sheppard L, Shepherd K, Sullivan JH, Anderson GL, Kaufman JD. Long-term exposure to air pollution and incidence of cardiovascular events in women. $\mathrm{N}$ Engl $\mathrm{J}$ Med. 2007;356(5):447-58.

13. Pearson TA, Blair SN, Daniels SR, Eckel RH, Fair JM, Fortmann SP, Franklin BA, Goldstein LB, Greenland P, Grundy SM, Hong Y. AHA guidelines for primary prevention of cardiovascular disease and stroke: 2002 update: consensus panel guide to comprehensive risk reduction for adult patients without coronary or other atherosclerotic vascular diseases. Circulation. 2002;106(3):388-91. 
14. Jackson R. Guidelines on preventing cardiovascular disease in clinical practice: Absolute risk rulesbut raises the question of population screening. BMJ. 2000;320(7236):659-61.

15. Huxley RR, Barzi F, Woo J, Giles G, Lam TH, Rahimi K, et al. A comparison of risk factors for mortality from heart failure in Asian and non-Asian populations: an overview of individual participant data from 32 prospective cohorts from the Asia-Pacific Region. BMC Cardiovasc Disord. 2014;14(1):61.

16. Agaba DC, Migisha R, Lugobe HM, Katamba G, Ashaba S. A 10-Year Risk of Cardiovascular Disease among Patients with Severe Mental Illness at Mbarara Regional Referral Hospital, Southwestern Uganda. BioMed Res. Int. 2020;2020.

17. Duerden M, O'Flynn N, Qureshi N. Cardiovascular risk assessment and lipid modification: NICE guideline. Br J Gen Pract. 2015;65(636):378-80.

18. Conroy RM, Pyörälä K, Fitzgerald AE, Sans S, Menotti A, De Backer G, De Bacquer D, Ducimetiere P, Jousilahti P, Keil U, Njølstad I. Estimation of ten-year risk of fatal cardiovascular disease in Europe: the SCORE project. Eur Heart J. 2003;24(11):987-1003.

19. D'Agostino RB, Grundy S, Sullivan LM, Wilson P. Validation of the Framingham coronary heart disease prediction scores: results of a multiple ethnic groups investigation. Jama. 2001;286(2):1807.

20. Pyorala K. Assessment of coronary heart disease risk in populations with different levels of risk. Eur Heart J. 2000;21:348-50.

21. WHO. 2014. Non-communicable Diseases Country Profiles 2014. Available from: http://apps.who.int/iris/bitstream/10665/128038/1/9789241507509_eng.pdf. [cited 2020 Dec 15].

22. American Diabetes Association. 2020. With prediabetes, action is the best medicine. Available from: https://www.diabetes.org/diabetes-risk/prediabetes?loc=superfooter. [cited 2020 Dec 15].

23. WHO. 2020. Hearts: technical package for cardiovascular disease management in primary health care. Available from: https://apps.who.int/iris/bitstream/handle/10665/333221/9789240001367eng.pdf [cited 2020 Dec 15].

24. Wang H, Naghavi M, Allen C, Barber RM, Bhutta ZA, Carter A, et al. Global, regional, and national life expectancy, all-cause mortality, and cause-specific mortality for 249 causes of death, 1980-2015: a systematic analysis for the Global Burden of Disease Study 2015. The Lancet. 2016;388(10053):1459-544.

25. Wang X, Dalmeijer GW, den Ruijter HM, Anderson TJ, Britton AR, Dekker J, et al. Clustering of cardiovascular risk factors and carotid intima-media thickness: The USE-IMT study. PLoS One. 2017;12(3):e0173393.

26. Möller-Leimkühler AM. Gender differences in cardiovascular disease and comorbid depression. Dialogues Clin Neurosci. 2007;9(1):71.

27. Jackson $R$, Chambless $L$, Higgins $M$, et al. Sex difference in ischemic heart disease mortality and risk factors in 46 communities: an ecologic analysis. WHO MONICA Project, and ARIC Study. Cardiovasc Risk Factors. 1997;7:43-54. 
28. Lönnberg L, Ekblom-Bak E, Damberg M. Reduced 10-year risk of developing cardiovascular disease after participating in a lifestyle programme in primary care. Ups J Med Sci. 2020;20:1-7.

29. Auler F, Nakashima AT, Cuman RK. Health conditions of recyclable waste pickers. J Community Health. 2014;39(1):17-22.

30. Cruvinel VR, Marques CP, Cardoso V, Novaes MR, Araújo WN, Angulo-Tuesta A, Escalda PM, Galato D, Brito P, da Silva EN. Health conditions and occupational risks in a novel group: waste pickers in the largest open garbage dump in Latin America. BMC Public Health. 2019;19(1):1-5.

31. Made F, Ntlebi V, Kootbodien T, Wilson K, Tlotleng N, Mathee A, Ndaba M, Kgalamono S, Naicker N. Illness. Self-Rated Health and Access to Medical Care among Waste Pickers in Landfill Sites in Johannesburg, South Africa. Int J Environ Res Public Health. 2020;17(7):2252.

32. Tay YH, Nurjono M, Lee J. Increased Framingham 10-year CVD risk in Chinese patients with schizophrenia. Schizophr Res. 2013;147(1):187-92.

33. Zhao S, Xia H, Mu J, Wang L, Zhu L, Wang A, Zhou X. 10-year CVD risk in Han Chinese mainland patients with schizophrenia. Psychiatry Res. 2018;264:322-6. 